\title{
Strategy Implementation and Performance of Micro Finance Institutions in Kenya. A Case of MFIS in Nairobi
}

\author{
Johnson Muteke Kianda $^{a}$, Brown Kitur ${ }^{b}$ \\ a Department of Business Administration, The Manageent University of Africa, \\ P Ob Box 29677-00100 Nairobi Kenya \\ ${ }^{\mathrm{b}}$ Deaprtment of Business Administration, The Management University of Africa, \\ P.O Box 29677 -00100, Nairobi Kenya. \\ ajkmuteke@gmail.com, bbkitur@mua.ac.ke
}

\begin{abstract}
Organizations face a myriad of challenges at times considering the nature of the current environment in which they exist, competition from other organizations in which they operate. The fast-changing technology, changing market demands, globalization, and investor demand for higher returns on their investment has forced the organizations to continually innovate in order to meet their objectives. This has been done by developing and implementing new strategies to improve their performance. This study aims at strategy implementation and performance of Micro Finance Institutions in Kenya, a case of Micro Finance Institutions in Nairobi. The objective of the study was to establish the influence of structure on performance. The findings of this study will be beneficial to the Micro Finance Institutions in Kenya and beyond, other similar organizations in the finance sector, the policy makers, Scholars, students, and researchers who may want to do further research on the gaps that may be realized from this study. The anchor theory was resource-based view theory reinforced by contingency theory, configuration theory and Kurt Lewin theory of motivation. The target population was 1573 and $10 \%$ of respondents were selected using a random stratified sampling method to select a sample that was to represent the population under study. The study adopted a descriptive design, targeting the senior management, supervisors, and non-management staff. The Questionnaire was utilized for data collection and the analysis of data using descriptive statistics was done The data collected was analyzed using descriptive statistics such as mean, average, and percentages. Pearson correlation show the relationship between the dependent and independent variables. The data was presented inform of tables and figures. The findings of each objective and conclusions were made. The study established that there was a positive relationship between organizational structure and
\end{abstract}


performance. The regression analysis also revealed that organizational structure and performance had a moderately significant relationship thus a unit change in performance could be explained by a change in organizational structure. The study recommends further research on other factors that influence performance in MFIS in Kenya.

Keywords: Organizational Culture; Organizational performance; Organizational structure

\subsection{The background of the study}

Globally Organizations exist to meet a certain need in society, and for this to be achieved they must position themselves strategically to maximize their own strengths and minimize weaknesses that impede them from achieving their goals. The environment today is very dynamic requiring high levels of flexibility, speed to produce and anticipate and adapt to an ever-changing environment and customer needs. Strategic Management is about careful processing and analysis of options available for organizations to exploit in order to enjoy its competitive advantage (Gregory, Lumpkin and Taylor, 2005). The organization must have a plan of action also known as the strategy that is clear on how to go about achieving their vision and mission within the given time frame and environment. Organizations are to think strategically, plan, translate their ideas into effective strategies so as to manage the ever-changing environment and meet their set goals. This calls for a game plan for growing their business, meeting customer demands, strategies to beat the competition, and position themselves in the market by conducting their operations in the most effective manner in order to achieve their target objectives Ulrich (1990) Organizations have to develop the rationale necessary for adopting and implementing formulated strategies. In order to achieve their objective, it was imperative for the organization to adjust to the external environment (Pearce and Robinson , 2003)

In Africa, Organizations face a myriad of challenges during the strategy implementation Process; these include lack of infrastructure, low levels of technological development as positions in organizations. Johnson and Scholes (2001) defines strategy as the method an organization employs over the long term giving it an advantage which builds value overtime to its stakeholders. A well-formulated strategy is good for an organization but a well-implemented strategy is better. Strategy implementation remains a major challenge to many organizations. Transforming strategies into action is far more complex, difficult, and time-consuming (Aaltonen and Ikavalkro, 2002.

In Kenya, organizations face a number of hurdles when implementing the strategies such as resistance to change, inadequate resources, lack of top management support during the times of transitions, and desire to safeguard personal interests instead of those of the organization and other times they lack the skills to deal with new changes that come with new strategies being implemented (Ochanda, 2005). The changing environment also poses a great challenge since the 
future is uncertain and organizations have to have room to accommodate such changes including the changing stakeholder expectations.

\subsection{Micro Finance Institutions in Kenya.}

The World Bank defines Micro Finance Institutions (MFIs) as institutions that engage in relatively small financial transactions using various methodologies to serve low income Households, Micro Enterprises, Small scale farmers, and others who lack access to traditional Banking services, CBS (1999). In another definition, the Microfinance Act, 2006, defines a Microfinance institution as a business receiving money by way of deposits and interest on deposits which is lent to others aroused to finance the business; or providing loans or other facilities to Micro or Small Enterprises and low-income households; deposit-taking and nondeposit taking (MFI Act, 2006). In Kenya, the government has had a keen interest in the progress of small-scale enterprises. This was assisted by partners such as Non- Governmental Organizations (NGOS) in collaboration with the government of Kenya. The government helped to set up the policy framework and platform for donor support which came through donorfunded credit facilities by the international financial institutions and United Nations and the commercial banks support (Muchina, 2005).

The Micro Finance Institutions are a unique combination of banking with social goals to improve the welfare of the less-resourced members of the society. The Micro Finance institutions play a vital role in the growth and development of economies by serving the lower-level members of the population previously ignored by the commercial banks by being considered too risky, currently, the banks serve $22.6 \%$ of the population and $18 \%$ by the Micro Finance Institutions. By effectively serving the poor population some of the MFIS successfully transformed to fullyfledged commercial banks such Equity bank, Family bank, Sidian Bank, Kenya Women Trust Bank (Mutua and Mirero 2005) According to (A comprehensive literature on Impact of Micro Finance, 2013) Microfinance can be used as a tool for empowerment as well as social protectionthrough savings, remittances, and insurance. Munene (2014) notes confidence in people is boosted by the non-financial services that Microfinance Institutions provide such as vocational skills training, consultancies, and advisories, and other social services.

A number of Micro finance institutions became fully commercialized and self-sustaining profitable institutions (Mwanthi, 2017. The Micro Finance Act, 2006, was meant to deal with issues such as; the regulation streamlined the issues of ownership, governance, management and accountability that had significantly affected many Micro finance institutions. A number of firms faced challenges related to diversity in institutional form, inadequate governance and management capability, limited outreach, unhealthy competition, and lack of performance standards. There are 13 registered Micro Finance Institutions (Also known as Micro Finance Banks) according to the Central Bank Supervisory report of 2018.

Micro finance is one of the ways of building capacities of the poor who were largely ignored by the banks by providing them with financial services such as credit, savings, and insurance. (Ananda kanwal, 2011). The performance of the Micro Finance institutions is assessed through 
the social performance-by ability to alleviate poverty through welfare and economic assessment through profitability and viability of the institutions. The Institutions school of thought of financial deepening is the main aim of Microfinance Institutions by setting a system for financial mediation for the underserved in the society.

The Kenya Micro Finance sector is one of the most vibrant in sub-Saharan Africa (FSD, Kenya, 2012). The Micro Finance act 2011 and Micro Finance regulations (2008) set out the legal regulatory and supervisory framework for the industry. The need for Microfinance was driven by a number of constraints mainly related to the structure and composition of the Kenya banking and finance sector, lack of appropriate regulation and governance required for the improvement in banking and finance conservative business practices of profit-focused banking institutions (Alastar, 2015). The main objective of every Microfinance institution is to have operations that are profitable in order to maintain stability and improve on sustainability and growth (Agola, 2014).

\subsection{Statement of the Problem}

The Strategic implementation process is core to the development of an organization. If the strategy formulation is done with excellence and strategy implementation is not well done, the whole process will have failed, because implementation will have a greater impact on the performance of the organization. Strategy Implementation will be said to have succeeded or failed depending on how well the implementation process utilizes the set funds, achieves the desired results in a timely manner, and meets the stakeholder's expectations. On the other hand, strategy implementation will have failed, if it doesn't bring the desired results, uses more resources and time than it was planned to take, or it doesn't change anything at all even upon complete implementation. The number of Micro Finances Institutions have experienced reduced returns in recent years according to the Central Bank of Kenya report (2018), there was a decline in profits. Which led to the amendment of the Microfinance Act (to strengthen capitalization, governance, management and ownership.

\subsection{The General Objective}

The objective of this research was strategy implementation and performance of Micro Finance Institutions in Kenya.

\subsubsection{Specific Objectives}

The study seeks to meet these specific objectives;

i. To examine the effect of organizational structure on performance of Micro Finance Institutions in Kenya.

ii. To analyze the effect of organizational culture on the performance of Micro Finance Institutions in Kenya

iii. To establish the effect of Leadership styles on the performance of Micro Finance Institutions in Kenya.

iv. To examine the influence of resource allocation on the performance of Micro Finance Institutions in Kenya. 


\subsection{The Significance of the Study}

The findings of the study will be valuable to the policymakers as they develop frameworks and guidelines in the area of Micro Finance Institutions. It will provide valuable information on the relationship of Strategy implementation and performance in the sector of Micro Finance.

The management of various financial institutions will find the study useful as they seek to understand the contribution of the study variables to performance. The Management of Microfinance institutions in Kenya will find the study particularly valuable as it will show the difference between those who carry out strategy implementation the value they get compared to those who do not. This will help the firms achieve success better through incorporating strategy implementation processes towards improving their performance.

The study will be valuable to the scholars and practitioners in the field of strategic management, it will help by contributing to the existing body of knowledge in the field of strategic management. The study will provide valuable background information to other researchers and scholars. It will help the individual researchers to identify gaps in this study and identify areas for further research.

\subsection{The Scope of the Study}

This research project looked at the strategy implementation and performance of Micro Finance Institutions in Kenya with reference to the Micro Finance institutions based in Nairobi County. The study targeted a population of 1573 out of which 157 of the respondents were randomly selected for the study. The study duration was from August 2020 to September, 2021.

\subsection{Literature Review}

\subsection{Theoretical Review}

\subsubsection{The Configuration Theory.}

The configuration theory was developed in the 1970s by Mitzberg and Miller and further improved Miles and Snow in 1987. The theory asserts that the execution of an organization is very reliable to the compatibility with the environment postulates on the fit of the environment and the organizational design. Its basic assumption is that an organization's best performance can be achieved when the organization's structure matches an external factor. According to Fincham and Rhodes, 2010) the theory assumes that for the firms to deliver there must be synchronization between strategy, structure and the environmental context. Studies on the theory have consistently established that it is fit among organizational characteristics as a significant predictor of an organization's performance (Slater and Olso, 2005) Geo, Zho and Yim (2007) any organization environment is exogenous hence the organization is to adjust its strategy according to the environmental constraints. In the context of this study, the theory brings out the link between company strategies and the external environment which determines organization performance on the choice of company strategy based on the changes in the background- as well as the fit between study variables and the strategy implementation. 


\subsubsection{Kurt Lewin Theory}

The kurt Lewin theory three-step model of change is very key in times of strategy implementation, the model has three stages of change namely unfreezing, planned change and refreeze. The unfreezing stage is where the organization realizes that though things could be going on well; there are better, more efficient ways of working to get results. The members of the organization are at a mental state that is comfortable and are not open to change. The people within the organization will work until a time where they feel dissatisfied with the current state of affairs (Cummings and Worley, 2003).Barnes (2004) identified change as a feature of organizational life for both strategic and operational levels, hence its importance. There is a need for behavior change in some aspects in order to meet the organizational goals by getting rid of outdated methods, processes, and behavior. The organization then initiates steps towards a new way of doing things that will benefit both parties within it. Organizational change, in particular, is complex, hence executing a well-planned change process doesn't always guarantee results, but it is worth trying. The Planned Change stage occurs when new processes and procedures are put in place and new behavior is adopted. The stability is achieved by utilization and supporting systems and measures that reinforce the new norms, values, policies, and practices that the organization needs at this new level of change For the process to be successful the new change needs to be permanent and become part of the organizational life and put system in place that ensures the organization doesn't drift back to the old ways especially when experiencing challenges with the new state. The above theory will be useful in connecting the development of organizational culture and the performance of Microfinance institutions in Kenya.

\subsubsection{Contingency Theory of Leadership}

The Contingency theory is a traditional approach mainly originating from organizational behavior and organizational management. It was developed based on premise that organizations will be efficient and achieve their set performance goals when they adapt to their own environment. The theory has been applied in the discipline of strategic management since 1975 when it was first used by Horfer 1975. Ginsberge and Venkratraman (1985) view strategy as a response to the external environment or as a factor that has a direct effect on performance on various spheres. The theory is found to advocate for the position that there is no one best way of organizations or appropriate form depends on the nature of the organization and the environment in which it operates. By close examination of the chosen strategy on performance, one finds contingent relationships are created because of the connection of influence of leadership style by organizational internal resources and external surroundings. The theory makes an effort to explain the methods of leadership tactics and styles used to provide guidance to the persons in the position of influence.. The theory is very useful in this study, as it helps to identify various abilities of leadership styles that fit in different organizations.

\subsubsection{Resource-Based View Theory}

The theory was reinvented in 1984 by Bireger Wernefelt. It was re-engineered in 1980 by Jay Barney through his study on "firm resources and sustained advantages "being very important in 
the emergence of the resource-based view. The theory was first developed by Penrose in 1959 but its relevance in analyzing business performance gained prominence through Wernerfelt's work in 1984 (Kozlenkova, Samaha, \& Palmatier, 2014). Jay Barney further advance made the theory more relevant by advancing its merits in influential work in strategic management studies. In his 1991 study on "firm resources and sustained advantages" outlined the main characteristics of internal resources and their relationship with competitive advantages. A firm achieves competitive advantages when "it is able to generate more economic value than the marginal competitor in its product market (Kozlenkova, Samaha, \& Palmatier, 2014). In his later work distinguished competitive advantage from a sustained competitive advantage (SCA). Barney stated that a firm achieved SCA when it achieves both competitive advantage and when other competing firms are unable to imitate the benefits of its strategy. Resource-based view shows the role played by organization resources in between various organizations through competitive advantage. The capabilities and application on organizational performance (Zhang, 2019).Kozlenkora, Samahas, and Palmatier (2014) the theory lies in the application of a bundle of valuable tangible as well as intangible resources at the firm's disposal. For an organization to transform a short-run competitive advantage into a sustained competitive advantage requires that the resources are as diverse in value as possible. This means that valuable resources are neither perfectly imitable nor interchangeable without great effort. The theory lays emphasis on the internal resources of the organization in developing its strategy to achieve sustainable competitive advantage in the marketplace. Resource-based view portrays the key role played by organizations in between various organizations competitive advantage, the capabilities and implications on the organization performance (Zhang, 2019). Organizations that adequately allocate resources have greater chances of improved performance compared to those that don't.

\subsection{Empirical Review}

Muumi et al (2018) analyzed the effect of the organizational structure of Micro Finance Institutions by looking at the variation of the legal structures and the business cycle timings across countries. Empirical results from the panel data of 1518 microfinance institutions from 105 countries over a period of 20 years provided results indicating that Microfinance institutions run by non-Governmental organizations have better social outreach compared to others run by commercial banks and credit unions. The results indicated Non-Governmental Organizations structure was better suited to achieve the dual objective of social outreach and financial selfsustainability.

Bhance (2013) examined the impact of the organizational structure on the performance of employees in the public service, in Kenya. The study aimed at examining the impact of organization structure on strategy implementation. The study adopted a research design and a cross-sectional questionnaire was used to collect data. A sample of 200 respondents was used to do the study. It was found that management behavior directly affected the output of the worker. The study recommended setting up structures that supported the positive behavior of the managers in order to consequently ensure positive performance.

Kyalo (2015) did a study to establish how strategy implementation influenced performance at Kenya Commercial Bank. A case study design was used and an in-depth interview to top 
managers was conducted, the study identified some of the factors that affected performance in strategy implementation to include capabilities of the leadership team, adequate resources allocation, having strategy supportive policies. The study revealed that strategy implementation is a key factor in the improved performance of an organization. The study recommended the development of the Leadership team to be able to adapt to different situations.

Mailu, Ntale and Ngui (2018) did a study on the pharmaceutical industry in Kenya. The study looked at the effect of strategy implementation on the performance of the organization. The study applied a descriptive survey research design and the target population comprised of all the 64 pharmaceutical companies located in Nairobi. The questionnaire was used for collecting data and the data was later analyzed using descriptive statistics. The study found that the adoption of strategy implementation positively and significantly affected performance of the organizations. The study established that organizational structure, organizational culture and organizational resources had a significant effect on performance. The study recommended empowering the employees so that they can fully utilize the structures in place to deliver the desired results.

A study by Khayota (2014) established that organizational structure was a key player in the success of the execution of strategies in the Lake Victoria South Water and Services Board. Establishing the most appropriate structure for an organization can be a daunting task because the process is constrained by such as size, technology, external environment and the strategies employed. The most favorable could be established by how complex, stable, diverse the environment is (John and Meier, 2011).

\subsection{Conceptual Framework}

The conceptual framework model was adopted for the study derived from the literature review and the variables on the framework have been used to develop research questions that were used for data collection.

\section{Independent Variable}

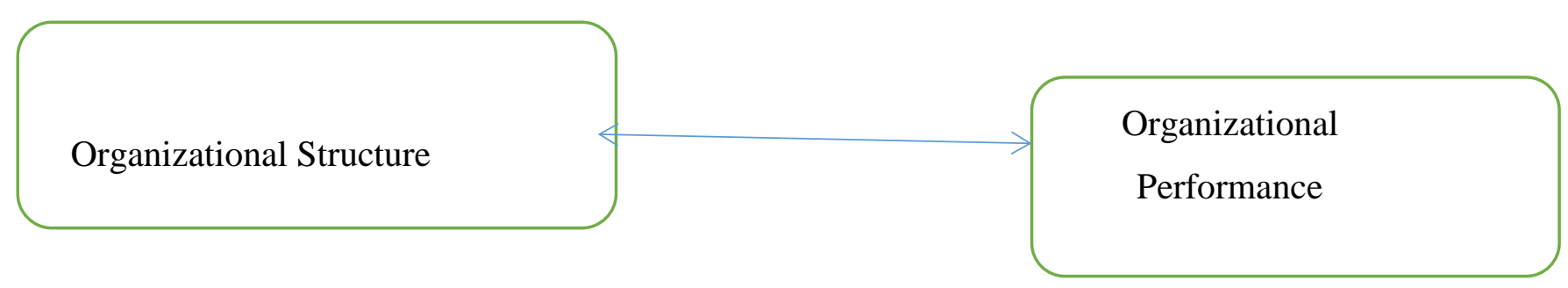

\section{Figure 2.1 Conceptual framework}

\subsection{Research Design}

According to Kothari (2009) a research design is an arrangement of the procedures for data collection and its analysis in a way that determines the relevance of the research purpose with procedure hence its conceptual structure within which the study is conducted. The study population was the staff members of various MFIS within Nairobi County. The study target was senior managers, middle managers, and non-management staff of 13 microfinance institutions within Nairobi County. 
Kothari (2009) defines a sample as a subject of the population that is selected to represent the characteristics of the population (Kothari 2009) Sample drawn randomly is unbiased in a way that no number of populations has any chance of being selected more than another. It is key to do sampling since it is good in saving time as well as expenses which could perhaps be consumed if one decided a study of the whole population in general (Robson, 2012). Random stratified sampling was used to draw a sample for this study. Based on the above population with 1573 respondents, from the whole population, the researcher selected 10 percent. Therefore, the research achieved a total of 157 respondents. Cooper and Schindler (2003) posit that a sample that is representative is the one that is $10 \%$ and above of the overall population and therefore choosing the 10 percent was deemed, representative. In addition, Mugenda and Mugenda (2003) positions that size of a sample that ranges from 10-30 percent of the overall population is sufficient for any kind of academic study, stratified random sampling approach was applied because the targeted population was not homogeneous and thus was classified into strata or groups for purposes of getting a sample that is representative.

\subsection{Target Population}

According to Saunders, Lewis and Thornbill (2016) target population represents an entire group of persons or things with similar features that are preferred by the investigator. It consists of a group of entities distinct from the sampled group where researcher draws the conclusions

Cooper and Schindler (2016) define target population as the total collection of elements which one wishes to generalize the research conclusion. This is a collective set that includes all the members in the research; objects or events, hypothetical or real groups of individuals from where the investigator intends to make a generalization of outcomes (Frederic, 2010). The study will target senior managers, middle managers, and non-management staff of 13 microfinance institutions within Nairobi County.

\subsection{Research Instruments}

Questionnaire was used for data collection for this study. Kombo and Trump (2009) describe questionnaire as a list of standard questions designed to get a particular inquiry. A questionnaire is an instrument of research that contains questions on the variables of the study. (Kothari, 2004).The researcher used questionnaires that were found to be effective, economical for the study. The instrument was key in ensuring anonymity. The questionnaires were divided into two sections namely; personal information and the study questions part. According to Orodho (2009), each objective should be addressed adequately by a particular section within the questionnaire. Cooper Schindler (2016) posits that self-administered methods are appropriate when it's necessary to have adequate time to consider and respond to the questionnaire as was the case with this study. The decision to use this method was aimed at ensuring the quality of the data collected.

\subsection{Data Collection Procedure}

After getting consent from the University, and a license from the National Commission of Science and Technology and Innovation, The researcher made a trip to various Micro Finance Institutions branches in order to get permission to do the research with them. A structured 
questionnaire was employed, which was very helpful in getting the results in good time for a large population. The questions offer the advantage of being quick and easy to answer as well as to keep the answers within the objective facts that questions aim to collect. (Burns and Ryman, 2008). Closed-ended questions on this study were structured with a five-point Likert scale with options ranging from strongly agrees to strongly disagree. The previous review found the point that Likert scale is a very effective technique in data collection. This study applied closed-ended questions on a five Likert scale designed with research objectives. The researcher then distributed the questionnaires to respondents in their places of work. A drop and pick approach was applied giving respondents sufficient time to fully work on those instruments. The researcher also engaged an assistant who assisted with the data collection. After completing, the researcher collected the issued questionnaires from the respective participants.

\subsection{Data Analysis and Presentation}

Before processing, the questionnaires were checked for completeness and accuracy. Coding of the data was done for enabling the grouping of responses into different categories. The nature of the collected data was both qualitative and quantitative in nature. Analysis was then carried out qualitatively and quantitatively through the application of descriptive statistics. This included the use of standard deviation, mean, and percentages whose presentation will be by use of tables and bar charts for purposes of giving a clear view of the outcomes of the research.

$\mathrm{Y}=\beta_{0}+\beta_{1} \mathrm{X}_{1}+\mathrm{e}$

Where,

$\mathrm{Y}$ : the dependent variable

Organizational performance) expressed as a linear combination of independent variables $\mathrm{X}_{1}, \mathrm{X}_{2}$, $\mathrm{X}_{3}$ and $\mathrm{X}_{4}$

$\beta_{0}$ : The regression constant

$\beta_{1}$ : Coefficient of organizational structure (independent variable $\mathrm{X}_{1}$ )

E: Error term

\subsection{Ethical Considerations}

Ethics refers to norms of behavior that differentiate between the behaviors which is acceptable and ones that are not. Ethics refers focuses on the conduct of an individual and guides the behavior. It is an important cork in research since it ensures that researchers stick to the objective of the study and do not have a personal gain or benefit from the exercise. It also ensures researchers do not engage in activities that adversely affect other people negatively. Bryman and Bell (2011) provide a comprehensive checklist of ten ethical considerations students should consider when undertaking research these include 


\subsection{Informed Consent}

The researcher sought permission to conduct the study from the participants before carrying out the collection of data. The reading and discussion of the consent forms was done by the research assistants to all the participants in English. This form was to give a description of the research purpose and information concerning voluntary participation as well as withdrawal from the research.

\subsection{Voluntary Participation}

The researcher then got informed consent from the participants and ensured that their participation was voluntary. This was done by seeking personal consent from every participant and sharing the authorization letter obtained from the University. The willing respondents were the only ones given the questionnaires to fill for purposes of collecting data.

\subsection{Confidentiality}

The researcher ensured truthfulness and transparency were kept during the review and confidentiality was guaranteed for all the gathered information. The researcher guaranteed the information gotten from the staff, first by assuring the respondents of the same, and secondly by not allowing them to include their names and those of the organizations they represented.

\subsection{The findings and presentation}

\subsection{Regression Analysis of Organizational Structure}

Table 1 Correlation between Organizational Structure and Performance

Organizational Performance

Pearson of Correlation $\quad 0.651 * * *$

Organizational structure

$\operatorname{sig}(2$ Tailed)

0.000

$\mathrm{N}$

99

**Correlation is significant at level of 0.01 of level (2 -Tailed)

The Pearson correlation analysis was carried out to establish the relationship between Organizational Structure and Performance. The study established that a strong positive relation between variables $(r=0.651, P=0.000)$ as shown in the table above. Consequently an increase in organizational structure will result to improved performance. 
Table 2 Regression Coefficients for Organizational Structure

\begin{tabular}{|c|c|c|c|c|c|c|c|}
\hline \multirow[t]{3}{*}{ Model } & \multicolumn{2}{|c|}{$\begin{array}{l}\text { Unstandardized } \\
\text { Coefficients }\end{array}$} & \multirow{3}{*}{$\begin{array}{l}\text { Standardized } \\
\text { Coefficients } \\
\text { Beta }\end{array}$} & \multirow[t]{3}{*}{$\mathrm{t}$} & \multirow[t]{3}{*}{ Sig. } & \multicolumn{2}{|c|}{$\begin{array}{l}95.0 \% \text { Confidence } \\
\text { Interval for B }\end{array}$} \\
\hline & & Std. & & & & Lower & Upper \\
\hline & & Error & & & & Bound & Bound \\
\hline (Constant) & 0.294 & .306 & & 3.309 & .001 & .314 & 0.904 \\
\hline $\begin{array}{l}\text { Organizational } \\
\text { structure }\end{array}$ & .227 & .101 & .218 & 2.235 & .000 & .025 & .428 \\
\hline
\end{tabular}

a. Dependent Variable: Organization performance

Organizational Performance $=0.294+.227+\mathrm{e}$ (Organizational structure)

The study findings indicated that the addition of organizational structure to Microfinance institutions has a significant positive impact on organization performance. The results indicate that there is a significant relationship between organizational structure and organization performance; $\mathrm{p}<0.05(\mathrm{P}=$ 0.01). Thus, the values of organizational structure are statistically significant $(\mathrm{t}=2.235, \mathrm{p}<.05)$ which means an increase in the mean index of organizational structure should increase organization performance by a positive unit mean index value of $.227(27.7 \%)$.

Table 3 Model Summary

\begin{tabular}{lrrrr}
\hline Model & R & R Square & Adjusted R square & \multicolumn{2}{c}{ Std. Error of the Estimate } \\
\hline 1 & $.773^{\mathrm{a}}$ & .598 & .581 & .21873
\end{tabular}

a. Predictors: (Constant), Organizational Structure

The study used the coefficient of determinants to evaluate the model's fit. The adjusted R2 also called $^{\text {the }}$ coefficient of multiple determinants is the percentage of variance in the dependent variable explained jointly by the independent variables. The model had an average adjusted coefficient of determination of .581 which implied that $58.1 \%$ of the variation on Performance of Microfinance institutions in Kenya can be explained by the independent variables under the study, namely Structure, organizational culture, Leadership styles, and Allocation of resources. The study further tested the significance of the model by the use of the ANOVA technique. 
Table 4 Summary of the Analysis of Variables

\begin{tabular}{rlrrrrr}
\hline Model & \multicolumn{1}{c}{$\begin{array}{l}\text { Sum of } \\
\text { Squares }\end{array}$} & df & Mean Square & F & Sig. \\
& & & & & & \\
\hline \multirow{2}{*}{1} & Regression & 6.695 & 4 & 1.674 & 34.984 & $.000^{\mathrm{b}}$ \\
& Residual & 4.497 & 94 & .048 & & \\
& Total & 11.192 & 98 & & & \\
\hline
\end{tabular}

a. Dependent Variable: Performance of Micro Finance Institutions

b. Predictors: (Constant), Organizational Structure

From the above results, the study shows that the regression model has a significant level of $0.00 \%$. Which shows the data is ideal for making conclusions on data parameters since the value of the significance is ( $\mathrm{P}=$ value) was less than 0.05 . The calculated value is greater than the critical value hence the organizational structure, the organizational culture, leadership style and allocation of resources have significance to performance. The significance value was less than 0.05 showing that the model was significant.

The study also used the table of co-efficient to determine the model. The findings are presented as below in table 5

\section{Table 5 The Co-efficient}

\begin{tabular}{|c|c|c|c|c|c|}
\hline \multirow[t]{2}{*}{ Model } & \multicolumn{2}{|c|}{$\begin{array}{c}\text { Unstandardized } \\
\text { Co efficient }\end{array}$} & \multirow{2}{*}{$\begin{array}{c}\text { Standardize } \\
\text { Beta }\end{array}$} & \multirow[t]{2}{*}{$\mathrm{T}$} & \multirow[t]{2}{*}{ Sig. } \\
\hline & B & Std. Error & & & \\
\hline (Constant) & .294 & .306 & & .961 & .339 \\
\hline Structure & .227 & .101 & .218 & 2.235 & .028 \\
\hline
\end{tabular}


From the above the SPSS generated output as presented in table above, the equation $\left(\mathbf{Y}=\boldsymbol{\beta}_{\mathbf{0}}+\right.$ $\left.\boldsymbol{\beta}_{\mathbf{1}} \mathbf{X}_{\mathbf{1}}+\boldsymbol{\beta}_{\mathbf{2}} \mathbf{X}_{\mathbf{2}}+\boldsymbol{\beta}_{\mathbf{3}} \mathbf{X}_{\mathbf{3}}+\boldsymbol{\beta}_{\mathbf{4}} \mathbf{X}_{\mathbf{4}}+\boldsymbol{\varepsilon}\right)$ becomes:

$\mathrm{Y}=.294+0.227 \mathrm{X} 3$

A unit change in Structure will result in a 0.227 positive change in performance while holding other factors constant.

\subsection{The Organizational Structure and Performance of MFIS in Kenya.}

The first objective was to determine the effect of organizational structure on the performance of Micro Finance institutions in Kenya. The study variable was assessed by requiring the respondents to use a five-point Likert scale and the researcher sought to examine how the organizational structure affects the performance of Micro Finance Institutions in kenya. The findings revealed that the variable organizational structure had an overall aggregate mean score of 22.42 and a standard deviation of 1.3799. This implied that Organizational structure had a significant effect on the performance of MFIS in Kenya. The values of $F=75.141$ show that cost Organizational structure is statistically and significantly affects organization performance which means the regression model is a good fit of the data and that organizational structure significantly influences the performance of MFIS in Kenya.

This on average affirmed the significant contribution by the structure to performance. The regression revealed a strong relationship $\mathrm{R}=0.601$ which showed a strong positive correlation and the structure is fundamentally related with $\mathrm{R}^{2}=0.361$ and revealed a strong relationship and implies that for every one unit change in performance, $36 \%$ is as a result of structure in the organization. (Rajaseker (2014) organizations structure provides a visual explanation of the decision-making process and resource allocation. The findings were very consistent with the other scholars such as Muumi (2018).

\subsection{The conclusion}

From the study findings, the predictor variables had an influence on the performance of Microfinance Institutions in Kenya. The regression analysis revealed a relationship that showed a strong positive correlation and revealed that organizational structure and organizational performance are fundamentally related, and the variation in organizational performance can be explained by a unit change in organizational structure. The study concludes that that organizational structure statistically and significantly affects organization performance which means the regression model is a good fit of the data and that cost Organizational structure significantly influences the performance of Micro Finance Institutions in Kenya.

\section{References}

Gregory, G. Dess., Lumpkin, T., and Marilyn, T. (2005), Competitive. Intelligence Strategic Management. (2 Ed.) New York: McGraw-Hill Irwin.

Johnson, G. \& Scholes, K. (2003) Exploring Corporate Strategy, (6th Ed). Prentice-Hall: London. 
Aaltonen, J., \& Ikåvalko, H. (2002). Implementing strategies successfully. Integrated management systems, 13(6), 123-212

Ochanda, R.(2005) Challenges of Strategy Implementation at Kenya Industrial Estates Limited, Unpublished Research Project University of Nairobi.

Muchina, W. Njagi. (2013) Relationship between Strategy Implementation and Performance of Commercial Banks in Kenya. Unpublished Research project. University of Nairobi.

Mwanthi. T. N. (2017) Linking Strategy Implementation with Organizational Performance in Kenya Universities. Unpublished MBA Research Project .University of Nairobi.

Orodho, A. J. (2009). Techniques of Writing Research Projects and Reports: In Education and Social Sciences. Department of Educational Management, Policy and Curriculum Studies. Maseno, Kenya: Kenzia Publishers.

Anand, R., \& Kanwal, A. (2011). Financial Performance of Microfinance Institutions: Bank Vs NBFC. International Journal of Management and Strategy, 2(2), 1-14.

Alastair, M., S. (2015). Inclusive Growth: Improving Microfinance Regulation to Support Growth and Innovation in Micro-enterprise: The Republic of Kenya Background Country Report. Economic and Social Research Council.

Agola, T. (2014). Credit Policy and Financial Performance of Microfinance Institutions in Kenya. Unpublished MBA Project. University of Nairobi, Kenya

Pearce, J. A., \& Robinson, R. B. (2011). Strategic Management: Formulation, Implementation and Control . New York: McGraw Hill.

Barnes, B., Burner. (2004) Managing change, A strategic approach to organizational dynamics $\left(4^{\text {th }}\right.$ ed). Prentice Hall: Harlow.

Bryman, A., \& Bell, E. (2011). Business Research Methods. 3rd ed. Oxford : Oxford University Press.

Cooper, C. \& Schidler, M. (2003). Multi method Research: A Synthesis of Styles: London: Sage Publication.

Cooper, D., \& Schindler, P. S.(2016). Business Research Methods. New Delhi: McGraw

David, R. (2003). Strategic Management: Concepts and Cases. (9th edition), Prentice Education Australia Pty Ltd: French's Forest.

Frederic, C. (2010) Using Trade to Enforce International Environmental Law: Implications for United States Law, 273, 276.

Hill. L., \& Jones, G. (2001). Essentials of Strategic Management (2nd ed.). Mason, Ohio: C. engage Learning.

Johnson, G., \& Scholes, K. (2002), Exploring Corporate Strategy, ( $6^{\text {th }}$ Edition) Prentice Hall.

Kombo, K. \& Tromp, D, (2006) Proposal and thesis writing: An Introduction/Nairobi, Kenya: Paulines publications Africa

Kothari, C. (2009). Research Methodology: Methods and Techniques (2nd Ed.). New Delhi, India: New Age International Publishers.

Mailu, R. N., Ntale, J. F. \& Ngui, T. K. (2018). Strategy Implementation and Organizational Performance in the Pharmaceutical Industry in Kenya. International Academic Journal of Human Resource and Business Administration, 3(2), 33-47 
Mugenda, O. \& Mugenda, A. (2002). Research Methods: Quantitative and Qualitative Approaches

Mugenda, O.M. \& Mugenda, A. G. (2003). Research Methods: Quantitative and Qualitative Approaches, Nairobi: Acts Press.

Muumi, N., M. (2018). The Role of Executive Development In Strategy Implementation. Unpublished MBA Project, University of Nairobi.

Orodho, G. (2013). The Practice of Social Research (7th Ed.). Boston: Wadsworth Publishing Company.

Pearce II, J., .A. \& Robinson, R., B. (2011). Strategic Management formulation, implementation and Control ;(12th Ed). New Delhi:

Tata Mcgraw-Hill

Kothari C.R (2006) Research Methodology Methods and Techniques, New Age journal of Management and Business research (A) Volume XV Issue X version 1

Ravasi, D., \& Schultz, M. (2006). Responding to Organizational Identity Threats: Exploring the Role of Organizational Culture. Academy of Management Journal, Vol. 41, pp. 433-458.

Saunders, M,. Lewis, p., \& Thornbill, A.(2016) Research Methods for Business Students Pearson education. New York

Muumi, N., M. (2018). The Role of Executive Development In Strategy Implementation. Unpublished MBA Project, University of Nairobi. 